\title{
A LITERATURA E O GÊNERO POESIA NO ÂMBITO DO ENSINO INFANTIL DA EDUCAÇÃO BÁSICA
}

\author{
Jucenilton Alves dos Santos ${ }^{1}$
}

\begin{abstract}
RESUMO: A presente pesquisa tem a finalidade de provocar e suscitar, em quem possa lê-la, a percepção indispensável e necessária para 0 entendimento do processo e da dinâmica poética/literária dentro das instituições escolares, especificamente na educação infantil. Dessa forma, torna-se relevante uma vez que o interesse pela educação infantil e, em particular, pelo gênero poesia, nos estimula a uma reflexão sobre o momento atual da prática desse gênero na escola de ensino fundamental de nosso país. A poesia vem desempenhando, ao longo da história, um importante papel no desenvolvimento das crianças no que se refere à aprendizagem da leitura e escrita e os processos cognitivos, contribuindo para a aquisição de hábitos e valores indispensáveis ao exercício pleno da oralidade. Sabe-se que a poesia pode ser uma grande contribuição para tornar a escola mais prazerosa e um ambiente mais alegre e favorável à aprendizagem. Portanto, o objetivo desse estudo de ordem bibliográfica é investigar as contribuições que o uso da poesia pode proporcionar no desenvolvimento das crianças na educação infantil e inserir as crianças no universo poético, familiarizando-as com a linguagem poética e com a forma gráfica dos textos poéticos.
\end{abstract}

PALAVRAS-CHAVE: Poesia. Ensino. Educação infantil. Educação Básica.

\section{Iniciando a conversa}

O objetivo desse estudo de ordem bibliográfica é investigar as contribuições que o uso da poesia pode proporcionar no desenvolvimento das crianças na educação infantil e inserir as crianças no universo poético, familiarizando-as com a linguagem poética e com a forma gráfica dos textos poéticos.

A poesia representa uma fonte de estímulos que instiga o indivíduo ao desenvolvimento da autoestima, desenvolve o raciocínio, a criatividade e coloca o indivíduo numa posição de engrandecimento tanto no emocional como no lado cognitivo, além da mediação nos processos de leitura e escrita. A poesia tem como finalidade o facilitar e ampliar o aprendizado com grande vantagem no processo de desinibição e desempenho da expressão oral.

Partindo dos pressupostos citados acerca das vantagens que a poesia tem em relação ao ensino e aprendizagem, faz-se necessário discutir esse tema tão importante e significativo como ferramenta pedagógica na educação infantil.

\footnotetext{
${ }^{1}$ Especialista em Gestão Escolar pela Universidade Federal da Bahia (UFBA), Graduação e Mestrado em Letras pela Universidade Estadual do Sudoeste da Bahia (UESB); Coordenador Técnico-Pedagógico na Secretaria Municipal de Educação e Cultura de Itiruçu-Bahia. Email: jucenilton@gmail.com
} 
Portanto, o objetivo geral da presente pesquisa é investigar as contribuições que o ensino de poesia pode proporcionar no desenvolvimento das crianças na educação infantil. Quanto aos objetivos específicos esperamos: verificar a importância do aprendizado de poesia na socialização e aprendizagem, conhecer a dinâmica do ensino de poesia na educação infantil, perceber as formas de interação da poesia com os demais eixos de trabalho nesta fase da escolarização e analisar as contribuições que o ensino de poesia pode proporcionar no desenvolvimento das crianças na educação infantil.

A importância de se pesquisar acerca dessa temática é bastante peculiar e muito significativa. É uma pesquisa bibliográfica e o conhecimento teórico que fundamenta essa investigação são os estudos de renomados autores referenciados, Referencial Curricular Nacional para a Educação Infantil, Parâmetros Curriculares Nacionais - PCNs, entre outros. Com esse trabalho espera-se suscitar uma reflexão na ação, a partir de uma abordagem sociointeracionista da educação, ao reconhecer a poesia como ferramenta mediadora da aprendizagem.

\section{Breve história da infância}

A história da infância é fruto de uma construção social, porém, percebe-se que sempre houve criança, mas nem sempre infância. São vários os tempos da infância, estes apresentam realidades e representações diversas, porque nossa sociedade foi constituindo-se de uma forma, em que ser criança começa a ganhar importância e suas necessidades estão sendo valorizadas, para que seu desenvolvimento seja da melhor forma possível, e que tudo aconteça no seu verdadeiro tempo. A infância precisa ser entendida como categoria social de efetiva importância para a sociedade. Com a sua valorização e respeito, construirá uma história diferenciada.

Ao longo do tempo, como mostra a história, surgiu diferentes concepções de infância. Primeiramente, a criança era vista como um adulto em miniatura (adulto centro), e seu cuidado e educação eram feitos pela família em especial pela mãe. Ainda existiam instituições alternativas que serviam para cuidado das crianças em situações desfavoráveis ou rejeitadas. Para Ariés, 
A descoberta da infância começou sem dúvida no século XIII, e sua evolução pode ser acompanhada na história da arte e na iconografia dos séculos XV e XVI. Mas os sinais de seu desenvolvimento particularmente numerosos e significativos a partir do fim do século XVI e durante o século XVII (ARIÉS, 1981 p. 65).

Antigamente o sentimento de infância era inexistente. Ariés (1981) relata que até mais ou menos por volta do século $\mathrm{XVI}$, não existia a particularidade da consciência sobre o universo infantil. A concepção de infância, até então, baseavase no abandono, pobreza, favor e caridade, desta forma era oferecido atendimento precário as crianças; havia ainda grande número de mortalidade infantil, devido ao grande risco de morte pós-natal e às péssimas condições de saúde e higiene da população em geral, e das crianças em particular. Em decorrência destas condições, uma criança morta era substituída por outros e sucessivos nascimentos, pois ainda não havia, conforme hoje existe, o sentimento de cuidado, ou paparicação (ARIÉS, 1981), pois as famílias, naquela época, entendiam que a criança que morresse não faria falta e qualquer outra poderia ocupar o seu lugar.

A falta de uma história da infância e seu registro historiográfico tardio é um indício da incapacidade por parte do adulto de ver a criança em sua perspectiva histórica. Somente nos últimos anos o campo historiográfico rompeu com as rígidas regras da investigação tradicional, institucional e política, para abordar temas e problemas vinculados à história social (ARIÉS, 1981).

De acordo os aportes teóricos de Ariés (1981), a infância é um fenômeno histórico e não meramente natural, e as características da mesma no ocidente moderno podem ser esquematicamente delineadas a partir da heteronomia, da dependência e da obediência ao adulto em troca de proteção. Aceitando-se a tese de Ariés (1981), é preciso aceitar que a infância, tal qual é entendida hoje, resulta inexistente antes do século XVI.

A vida era relativamente igual para todas as idades, ou seja, não havia muitos estágios e os que existiam não eram tão claramente demarcados. Por exemplo, as crianças tinham muito menos poder do que atualmente têm em relação aos adultos. Provavelmente ficavam mais expostas à violência dos mais velhos, segundo Ariés (1981).

O autor acima referido demonstra a existência da infância como categoria autônoma diferenciada somente depois de um processo, que pode ser 
caracterizado como devolução nos sentimentos, ocorridos entre os séculos XVI e XVIII. O retrato de família predominante na arte do século XVIII mostra estes sujeitos, antes inexistentes, formando parte do centro do mundo familiar.

Durante a Idade Média, antes da escolarização das crianças, estas e os adultos compartilhavam os mesmos lugares e situações, fossem eles domésticos, de trabalho ou de festa. Na sociedade medieval não havia a divisão territorial e de atividades em função da idade dos indivíduos, não havia o sentimento de infância ou uma representação elaborada dessa fase da vida.

Dessa forma, foi durante o século XVII que se generalizou o hábito de pintar nos objetos e na mobília uma data solene para a família. Pode-se afirmar que foi na Idade Média que as "Idades da Vida" começaram a ter importância. Durante a Idade Média, então, existiam seis etapas de vida. As três primeiras, que correspondem à $1 \mathrm{a}$ idade (nascimento / 7 anos), 2a idade (7/ 14 anos) e 3a idade (14 - 21 anos) eram etapas não valorizadas pela sociedade. Somente a partir da $4 a$ idade, a juventude (21 - 45 anos), as pessoas começavam a ser reconhecidas socialmente. Ainda existiam a 5a idade (a senectude), considerando a pessoa que não era velha, mas que já tinha passado da juventude; e a 6a idade (a velhice), dos 60 anos em diante até a morte. Tais etapas alimentavam, desde esta época, a ideia de uma vida dividida em fases (ARIÉS, 1981).

Essas fases segundo Piaget (1972) são denominadas estágios do desenvolvimento: Estágio sensório-motor (do nascimento aos 2 anos); Estágio préoperacional (dos 2 anos aos 6 anos); Estágio das operações concretas (dos 6 anos aos 12 anos); Estágio das operações formais (a partir dos 12 anos). Ambos os estágios contempla a infância e suas especificidades dentro de seu contexto histórico. Para o autor em questão,

Cada estágio é caracterizado pela aparição de estruturas originais, cuja construção o distingue dos estágios anteriores. A cada estágio correspondem características momentâneas e secundárias que são modificadas pelo desenvolvimento ulterior, em função da necessidade de melhor organização. Cada estágio constitui (então pelas estruturas que o define) uma forma particular de equilíbrio, efetuando-se a evolução mental no sentido de uma equilibração sempre mais completa (PIAGET, 1972; p.83).

Outro teórico chamado Vygotsky (1989) ressalta essas fases como nível de desenvolvimento real: são todas as atividades que a criança já consegue fazer 
sozinha sem necessitar da ajuda de alguém; nível de desenvolvimento potencial: é o que a criança consegue fazer só com ajuda. Aqui, o resultado da ação é influenciado por outras pessoas; e por fim zona de desenvolvimento proximal: é a distância entre os dois níveis, ou seja, entre o nível de desenvolvimento real (o que a criança consegue fazer sozinha) e o nível de desenvolvimento potencial (o que a criança consegue realizar com a ajuda de outras pessoas para resolver problemas). Este nível de desenvolvimento está em constante transformação, pois o que a criança hoje é capaz de fazer com a ajuda de outra, amanhã conseguirá fazer sozinha, transformando depois este nível num nível de desenvolvimento real.

A infância acerca dessas fases é entendida, por um lado, como categoria social e como categoria da história humana englobando aspectos que afetam também o que temos chamado de adolescência ou juventude.

Por outro lado a infância é entendida como período da história de cada um que se estende, na nossa sociedade, do nascimento até aproximadamente dez anos de idade. A ideia da infância surgiu no contexto histórico social da modernidade com redução dos índices de mortalidade infantil, graças ao advento e avanço da ciência e a mudanças econômicas e sociais. Essa concepção para o autor nasceu nas classes médias e foi marcada por um duplo modo de ver as crianças.

Enfim, conclui-se que a partir dos aportes teóricos de Ariés (1981), podemos constatar que na antiguidade a criança era desvalorizada, simplesmente o sentimento pela infância não existia. Após o século XVII, houve grandes alterações nas relações sociais e, isto veio a refletir-se nas famílias, nas escolas e até mesmo no conceito dado à infância. Nos finais do século XVIII dá-se a Revolução Industrial na Europa. Portanto, as cidades crescem e com elas surge uma maior oferta de trabalho nas indústrias. As mulheres que antes ficavam responsáveis pelos afazeres domésticos e a cuidar dos filhos passam a ter que trabalhar. Daí, em contrapartida a tais necessidades de trabalho surgem às creches e instituições para cuidarem das crianças enquanto as mães trabalhavam. Durante o século XX surge um movimento internacional a favor da criança e, esta passa a ser alvo de atenções. 


\section{O gênero poesia e a importância do seu uso na sala de aula}

A poesia para as crianças vem de encontro ao desenvolvimento da imaginação, da expressão e da sensibilidade, assim como, o desenvolvimento da prática reflexiva que leva à criança a novas percepções, aguça a sensibilidade, a cognição e a imaginação.

Este gênero literário, quando visto como brincadeira, como jogo de palavras; ao ser memorizado e repetido, possibilita às crianças atentarem não só aos conteúdos, mas também à forma, aos aspectos sonoros da linguagem, como ritmos e rimas, além das questões culturais e afetivas envolvidas.

Assim, ao realizar com frequência a leitura de poesias, o professor estará propiciando às crianças oportunidade para que conheçam as características próprias deste, isto é, podendo senti-lo e identificá-lo quando escutado ou lido pela criança.

Os ganhos pedagógicos desse gênero em sala de aula propicia no âmbito prático e reflexivo a articulação dos seguintes aspectos: A escuta interessada de poesias, visando a percepção do sentido que o poema propõe e a capacidade de construção de sentido, reconhecimento, análise e identificação das obras e seus autores; A reflexão como um pensar sobre todos os conteúdos dos poemas, compartilhando perguntas e afirmações que a criança realiza instigada pelo professor a partir do contato com a poesia; O fazer poesia centrado na exploração, expressão e comunicação de produção de trabalhos com a ajuda do professor, propiciando o desenvolvimento de um percurso de criação pessoal.

O trabalho em torno das poesias em Educação Infantil visa às oportunidades para que as crianças sejam capazes de: ampliar gradativamente suas possibilidades de comunicação e expressão, interessando-se pela poesia; participar de diversas situações de intercâmbio social nas quais possa contar as poesias que conhece, ouvir outras, elaborar e responder perguntas; familiarizar-se com a escrita de poemas por meio do manuseio de livros, revistas e outros e da vivência de diversas situações nas quais seu uso se faça necessário; escutar poesias lidas, apreciando a leitura feita pelo professor, ampliando seu conhecimento de mundo e da cultura; interessar-se por criar poesias; ler poesias 
(quando já alfabetizado ou em processo de alfabetização) e fruir da poesia, sensibilização para com a leitura e escrita.

Ao iniciar a estratégia poética nas classes de educação Infantil, deve-se lembrar de que as cantigas populares e folclóricas, as canções de ninar, os versos de roda e os jogos são as experiências mais próximas que as crianças pequenas têm no campo da poesia.

E a maneira mais fácil de tratar Poesia com as crianças é apresentá-las: lendo, declamando, escutando, sentindo. Não descartando as que já sabem, mas sim aproveitando sua vivência para o trabalho com poetas que escrevem e escreveram para elas. Quanto a isso Martins, Picosque \& Guerra comenta:

\begin{abstract}
As aulas devem ser instantes mágicos, jogos de aprender e ensinar. $\mathrm{E}$ para isso requerem que o professor tenha mãos habilidosas que possam preparar e coordenar da maneira que escolha contextos significativos para os alunos tecerem sua rede de significações (MARTINS, PICOSQUE \& GUERRA 1998, p. 129).
\end{abstract}

Trabalhar poesia em sala de aula passa pela formação do professor que deve estar preparado e, ao ler um poema para classe, deve conhecê-lo bem: lido várias vezes antes, sentido, percebido e saboreado. Só assim irá passar a emoção verdadeira, o ritmo e a cadência e, assim, fazer com que os alunos possam perceber as passagens, estrofes e mudanças, como sugere Abramovich (1991).

Não é tarefa muito fácil, mas segundo Alves (2004) a melhor sugestão é que os escritores deveriam imitar os compositores e, para protegerem a beleza de suas poesias, deveriam colocar no início de sua obra a informação de como deve ser lida. Pois, há textos são marcados por uma alegria infantil e devem ser lidos ao ritmo de uma criança pulando corda e dando risada. Mas, quando o clima é de tristeza, deve ser lido lentamente, com sofrimento. Cabe ao professor instigar às crianças a descobrir o mundo da Poesia, seduzindo-as com ela, buscando poesias que tenham significações para elas, como brincadeiras e outras experiências infantis.

Para isso é preciso partir das preocupações que as crianças têm, pois, do contrário, só se conseguirá que decorem sem interesse os conhecimentos que deveriam ser apropriados por elas.

De acordo o documento Referencial Curricular Nacional para Educação Infantil (1998) é aconselhável que as crianças realizem uma observação livre da 
poesia - quando apresentada pelo professor e/ou escutada, quando musicada - e que possam tecer os comentários que quiserem, fazendo com que todo o grupo participe. E, o professor deverá atuar com um provocador da apreciação dos poemas, escolhendo e socializando as falas das crianças.

$O$ afim de que as aulas se tornem significativas através da poesia, o professor deve também aceitar os conhecimentos prévios das crianças e as informações que trazem de casa. Entendendo a mudança no papel do professor, que não é mais quem detém o saber, mas sim, quem detém a porta, a passagem, é quem faz a mediação. "E essa mediação não significa entupir o aluno de informações, significa, levar à criança a refletir, imaginar e criar (SODRÉ, 2002, p. 25).

Sabemos que a escola pode ensinar a ler, e também desenvolver um ensino de literatura que priorize o desenvolvimento de competências e habilidades relacionadas com o letramento literário, mas para que isso ocorra é necessário que ela se atualize, dando espaço para práticas culturais contemporâneas que são muito mais dinâmicas.

Dentro da literatura encontramos diversos gêneros textuais, cada um com suas características específicas e a poesia é um gênero rico em vários aspectos que devem ser considerado em uma sala de aula.

\section{A poesia como fonte de prazer e aprendizagem}

A Língua Portuguesa é um sistema que tem como centro a interação verbal a qual se faz através de textos diversos ou discursos falados e ou escritos.

Partindo desse pressuposto, trabalhar textos em sua diversidade valoriza 0 uso da língua em diferentes situações ou contextos sociais com a sua diversidade de funções e variedades de estilos e modo de falar. Nesse sentido a poesia é bastante significativa para que se alcance êxito nas etapas iniciais do gosto pelo poético.

Percebe-se que a poesia ainda é um gênero bastante desvalorizado no contexto escolar. Percebe-se em grande parte que os alunos não gostam de ler poemas e o professor acaba não conseguindo e nem mesmo encontrando meios para motivá-los a lerem textos poéticos. É possível enumerar diversos fatores responsáveis por este tipo de prática em sala de aula, a começar pelas falhas 
encontradas na formação do professor e na abordagem empobrecida da poesia nos livros didáticos de Língua Portuguesa. A grande maioria dos livros, quando tratam deste gênero em seu conteúdo, serve apenas como pretexto para estudos gramaticais ou para dar ênfase aos aspectos formais do poema. Porém, deve-se ter muito cuidado em tentar apontar um culpado na ocorrência destes aspectos, pois na verdade, não existe apenas um culpado, mas sim um conjunto de fatores que podem ser considerados responsáveis por esta situação.

A maioria dos professores sabe da importância da leitura da poesia durante 0 desenvolvimento escolar e humano dos alunos, mas em vez de assumir o seu papel de incentivar o trabalho com este gênero, acaba tratando a poesia de forma equivocada e superficial. Sabe-se que atualmente em nossa sociedade o hábito da leitura não é tão valorizado, este comportamento advêm de fatores socioculturais e políticos. Assim, é comum verificarmos que o conceito que se tem sobre leitura está restrito à mera decodificação das palavras, ou seja, tal mecanismo não oferece a oportunidade ao leitor de perceber os diversos sentidos contidos no texto.

Acredita-se que a poesia é uma ferramenta importantíssima pedagogicamente se falando para trabalhar leitura e escrita. Portanto, a temática se propõe a trabalhar com textos significativos visando à formação de alunos leitores, visto que os autores deste gênero empenham-se em mostrar seu pensamento sobre o mundo, a cultura, o meio social e a linguagem bastante diversificada.

Trabalhar a diversidade de textos, no sentido desse artigo, a poesia é muito importante, uma vez que o Referencial Curricular Nacional para a Educação Infantil, volume 3 aponta a linguagem oral e escrita como um dos eixos básicos na educação infantil.

A poesia deve ser usada como proposta de socialização, desenvolvimento e aprendizagem da leitura e escrita. $\mathrm{O}$ aprendizado da poesia deve ser um ato de desprendimento prazeroso, que comungue com as experiências da criança sem ser uma imposição ou que busque a qualquer custo que a criança domine rimas e falas sem prazer poético.

Portanto a importância da poesia para crianças é colaborar com o desenvolvimento da mesma, almejando que essa não seja apenas uma prática descontextualizada, mas um complemento, um meio para o melhor entendimento e trabalho das muitas atividades realizadas na educação infantil, que além de 
desenvolver a sensibilidade no aprendizado da leitura pode ainda ajudar no desenvolvimento de outras potencialidades da criança.

O Referencial Curricular Nacional Para Educação infantil - RCNEI (1998) compreende a poesia como linguagem e área de conhecimento, considerando que está tem estruturas e características próprias, devendo ser considerada como: produção, apreciação e reflexão.

O processo poético enquanto ferramenta pedagógica tem como propósito favorecer e colaborar no desenvolvimento dos alunos, sem privilegiar apenas alguns alunos, entendendo esta, não como uma atividade mecânica e pouco produtiva que se satisfaz com o recitar de algumas cantigas e em momentos específicos da rotina escolar, mas envolve uma atividade planejada e contextualizada, como prevê o RCNEI, além de explorar as múltiplas possibilidades que a poesia tem em seu ensino de leitura e escrita.

\footnotetext{
Além de produzir construções mais complexas as crianças são mais capazes de explicitações verbais... O desenvolvimento da fala e da capacidade simbólica amplia significativamente os recursos intelectuais. Porém, as falas infantis ainda são produtos, de uma perspectiva muito particular de um modo próprio de ver o mundo (RCNEI, 1998, p. 126).
}

Portanto, a poesia contribui na formação do indivíduo, como um todo, the dando oportunidade de imergir em um imenso universo cultural, enriquecendo sua inteligência através de sua sensibilidade poética, acerca do cognitivo, da sensibilidade e da própria personalidade.

Vê-se então que o Referencial Curricular Nacional para a Educação Infantil, no volume 3 - Conhecimento de mundo aponta a linguagem oral e escrita como um dos eixos básicos na educação infantil. E reconhece que a educação infantil deva promover experiências significativas de aprendizagem através de trabalhos com a linguagem oral e escrita que irão ampliar o modo como às crianças irão descobrir as regularidades da linguagem oral, se apropriando das convenções da língua.

Para atender às exigências da Lei de Diretrizes e Bases 9.394/96 que reconhece a Educação Infantil como primeira etapa do ciclo da Educação Básica o Referencial Curricular Nacional para a Educação Infantil, foi planejado tendo como um de seus objetivos incorporarem as atividades pedagógicas aos cuidados com 
as crianças. Outro dos objetivos trata da realidade social e cultural vivenciada pelas crianças.

\section{Algumas considerações}

O trabalho com poesia na escola ajuda os aprendizes aperfeiçoarem o vocabulário, a leitura, a linguagem oral, a entrarem em contato com a cultura e atingirem o universo da infância, estimulando desde cedo a consciência crítica de leitor.

Já não podemos pensar o ensino da escrita desconectado da leitura. Para ler um texto não basta identificar as letras, sílabas e palavras, é preciso buscar o sentido, compreender, interpretar, relacionar e reter o que for mais relevante.

Quando lemos alguma coisa, temos sempre um objetivo: buscar informação, ampliar conhecimento, meditar, entreter-nos. O objetivo da leitura é mobilizar as estratégias que o leitor vai utilizar. Sendo assim, ler um artigo de jornal é diferente de ler um romance, uma história em quadrinho ou um poema.

Geralmente, quando lemos uma poesia, temos como objetivo o entretenimento, a busca do encantamento com a forma original e diferente que os poetas têm de ver o mundo. Diferentemente de outros gêneros de texto, a poesia pode ser lida muitas vezes, e a cada leitura despertar uma nova emoção, novas ideias, novas sensações.

Por outro lado, ler poesias traz desafios para o leitor. É preciso buscar significados, sentidos, descobrir como o poeta "brincou com as palavras". Nossos alunos, na maioria das vezes, não têm familiaridade com a leitura de poesias. Assim, é tarefa nossa ajudá-los a vencer esse desafio, tarefa não muito fácil, mas, é um propósito desse artigo.

\section{THE LITERATURE AND THE GENDER POETRY IN THE FRAMEWORK OF CHILDREN'S EDUCATION IN BASIC EDUCATION}

\footnotetext{
ABSTRACT: The present research has the purpose of provoking and provoking, in those who can read it, the indispensable and necessary perception for the understanding of the process and the poetic / literary dynamics within the school institutions, specifically in the infantile education. In this way, it becomes relevant since the interest in children's education, and in particular, the poetry genre, stimulates us to reflect on the current moment of the practice of this genre in the elementary school
} 
of our country. Throughout history, poetry has played an important role in the development of children in reading and writing and cognitive processes, contributing to the acquisition of habits and values that are indispensable to the full exercise of orality. It is known that poetry can be a great contribution to make the school more pleasant and a more joyful and supportive environment for learning. Therefore, the purpose of this bibliographic study is to investigate the contributions that the use of poetry can provide in the development of children in early childhood education and to insert children into the poetic universe, familiarizing them with poetic language and the graphic form of poetic texts.

KEYWORDS: Poetry. Teaching. Child education. Basic education.

\section{Referências}

ABRAMOVICH, Fanny. Literatura infantil: gostosuras e bobices. 2 ed. São Paulo: Scipione, 1991.

ALVES, Rubem. Como ensinar o prazer de ler. São Paulo: Jornal Folha de São Paulo, suplemento Sinapse, 30/3/2004 a. Interpretar é compreender. São Paulo: Jornal Folha de São Paulo, suplemento Sinapse, 27/4/2004 b.

ARIÉS, Philippe. História social da criança e da família. $2^{\underline{a}}$ ed., Rio de Janeiro, LTC, 1981.

BRASIL. Ministério da Educação e do Desporto. Secretaria de Educação Fundamental. Referencial Curricular Nacional para a Educação Infantil. Volume I. Brasília, MEC/SEF, 1998.

- Ministério da Educação e do Desporto. Secretaria de Educação Fundamental. Referencial Curricular Nacional para a Educação Infantil. Volume II e III Brasília, MEC/SEF, 1998.

MARTINS, Mirian Celeste; PICOSQUE, Gisa \& GUERRA, Maria Terezinha Telles. Didática do ensino da arte: a língua do mundo - poetizar, fruir e conhecer arte. São Paulo: FTD, 1998.

PIAGET, J. A formação do símbolo na criança. $2^{\underline{a}}$ ed. Rio de Janeiro: Zahar, 1972. VYGOTSKY, Lev (1989). A Formação Social da mente. Editora: Martins Fontes. 
Data de Submissão: 26/10/2017

Data de Aprovação: 27/12/2017 